Article

\title{
Synthesis of Ternary Borocarbonitrides by High Temperature Pyrolysis of Ethane 1,2-Diamineborane
}

Fabrice Leardini ${ }^{1, *}$, Lorenzo Massimi ${ }^{2}$, Eduardo Flores-Cuevas ${ }^{1}$, Jose Francisco Fernández ${ }^{1}$, Jose Ramon Ares ${ }^{1}$, Maria Grazia Betti ${ }^{2}$ and Carlo Mariani ${ }^{2}$

${ }^{1}$ Departamento de Física de Materiales, Universidad Autónoma de Madrid, Madrid 28049, Spain; E-Mails: eduardoe.floresc@ gmail.com (E.F.-C.); josefrancisco.fernandez@uam.es (J.F.F.); joser.ares@uam.es (J.R.A.)

${ }^{2}$ Dipartimento di Fisica, Sapienza Università di Roma, Roma 00185, Italy;

E-Mails: lorenzo.massimi@ uniroma1.it (L.M.); maria.grazia.betti@ roma1.infn.it (M.G.B.); carlo.mariani@uniroma1.it (C.M.)

* Author to whom correspondence should be addressed; E-Mail: fabrice.leardini@uam.es; Tel.: +34-914-976-422; Fax: +34-914-978-579.

Academic Editor: Umit Demirci

Received: 26 May 2015 / Accepted: 24 August 2015 / Published: 9 September 2015

\begin{abstract}
Ethane 1,2-diamineborane (EDAB) is an alkyl-containing amine-borane adduct with improved hydrogen desorption properties as compared to ammonia borane. In this work, it is reported the high temperature thermolytic decomposition of EDAB. Thermolysis of EDAB has been investigated by concomitant thermogravimetry-differential thermal analysis-mass spectrometry experiments. EDAB shows up to four $\mathrm{H}_{2}$ desorption events below $1000{ }^{\circ} \mathrm{C}$. Small fractions of $\mathrm{CH}_{4}, \mathrm{C}_{2} \mathrm{H}_{4}$ and $\mathrm{CO} / \mathrm{CO}_{2}$ are also observed at moderate-high temperatures. The solid-state thermolysis product has been characterized by means of different structural and chemical methods, such as X-ray diffraction, Raman spectroscopy, Scanning electron microscopy, Elemental analysis, and X-ray photoelectron spectroscopy (XPS). The obtained results indicate the formation of a ternary borocarbonitride compound with a poorly-crystalline graphitic-like structure. By contrast, XPS measurements show that the surface is rich in carbon and nitrogen oxides, which is quite different to the bulk of the material.
\end{abstract}

Keywords: borocarbonitrides; graphitic materials; amine-borane adducts; thermolysis; X-ray photoelectron spectroscopy (XPS); Raman 


\section{Introduction}

Solid hydrides have received a considerable attention in the last two decades within the framework of hydrogen storage applications. Among them, amine-borane adducts have been widely investigated in the last few years, due to their high hydrogen content, both in terms of gravimetric and volumetric capacities, and the moderate conditions needed for hydrogen desorption [1-3]. The prototypic and more-investigated amine-borane adduct is ammonia borane $\left(\mathrm{NH}_{3} \mathrm{BH}_{3}, \mathrm{AB}\right.$ hereafter), which possesses the highest hydrogen gravimetric capacity among all amine-borane adducts and releases hydrogen at mild conditions. $\mathrm{AB}$ thermolysis takes place in three steps, evolving each step nearly one equivalent of $\mathrm{H}_{2}$ per $\mathrm{AB}$ equivalent. The first two steps occur at moderate temperatures $\left(<200{ }^{\circ} \mathrm{C}\right)$ and give rise to the formation of polymeric amino borane $\left(\left(\mathrm{NH}_{2} \mathrm{BH}_{2}\right)_{n}\right)$ and polymeric iminoborane $\left((\mathrm{NHBH})_{n}\right)$, respectively [4]. Small fractions of volatile by-products, such as diborane or borazine, are also observed. The third step occurs at much higher temperatures and gives rise to the formation of hexagonal boron nitride [5]. From the point of view of hydrogen storage applications, only the first two steps are of interest and have been investigated in detail. However, the use of $\mathrm{AB}$ as a precursor for the synthesis of hexagonal boron nitride ( $\mathrm{h}-\mathrm{BN}$ ) has experienced an increasing interest among the scientific community in recent times [6]. Indeed, h-BN is a ceramic material, showing a high oxidation resistance at elevated temperatures, thus providing numerous applications. In addition, two-dimensional h-BN, also called white graphene, is a very interesting two-dimensional material due to its complementary properties as compared to graphene [7-9], as well as an ideal substrate to grow graphene [10]. The synthesis of white graphene is usually done by chemical vapor deposition, using $\mathrm{AB}$ as a precursor $[11,12]$.

The previous examples show that the number of potential applications of solid hydrides, in particular of the amine-boranes, is well beyond the framework of hydrogen storage. In this work, we investigate the high temperature pyrolytic decomposition of a different amine-borane adduct, namely ethane 1,2-diamineborane $\left(\mathrm{BH}_{3} \mathrm{NH}_{2} \mathrm{CH}_{2} \mathrm{CH}_{2} \mathrm{NH}_{2} \mathrm{BH}_{3}\right.$, EDAB hereafter). The synthesis of this compound was reported in the early 1960s through two paths, and its structural and vibrational properties were also investigated [13-15]. However, the thermolysis of EDAB has not been reported until recently. EDAB evolves between four to five equivalents of $\mathrm{H}_{2}$ per formula unit below $250{ }^{\circ} \mathrm{C}$, forming a polymeric like derivative, with $\mathrm{B}-\mathrm{N}$ and $\mathrm{B}=\mathrm{N}$ bonds and maintaining $\mathrm{CH}_{2}$ groups in the chains [16,17]. A reasonably good reproducibility has been obtained comparing EDAB samples from different batches and synthetic routes.

It is expected that $\mathrm{H}$ atoms remaining in the polymer obtained at moderate temperature pyrolysis evolve at higher temperatures, thus forming a $\mathrm{B}_{x} \mathrm{C}_{y} \mathrm{~N}_{z}$ ceramic compound. It is therefore of interest to further investigate the pyrolysis of $\mathrm{EDAB}$ up to higher temperatures and characterize the obtained boro-carbo-nitrides. Hexagonal borocarbonitrides are of interest for the wide range of applications associated to the graphene-related technology, as well as for electrocatalysis and heat storage applications. Such compounds have been prepared following different synthetic approaches, usually using at least two precursors simultaneously [18]. This work investigates a novel synthetic approach towards the formation of ternary borocarbonitrides. It is a simple method using a single precursor, namely, the high temperature thermolysis of EDAB. 


\section{Results and Discussion}

\subsection{Structural Characterization of EDAB Precursor}

The structural properties of the EDAB precursor have been investigated by X-ray powder diffraction (XRPD), as well as Fourier transformed infrared spectroscopy (FTIR). All diffraction peaks in the XRPD pattern of EDAB (see the Supplementary Information) can be indexed to Pbca space group characteristic of EDAB phase [19], with no traces of crystalline secondary phases. Rietveld refinement of the diffraction pattern gives the following lattice parameters, $a=10.709$ (1) $\AA, b=8.134(1) \AA$ and $c=8.092(1) \AA$, which are in good agreement with previously reported values $[17,19]$. Moreover, all modes appearing in FTIR spectrum of EDAB match quite well with previously reported [14,17], thus confirming the purity of the EDAB compound (see the Supplementary Information).

We also characterized the EDAB powder by X-ray photoelectron spectroscopy (XPS) prior to pyrolysis. As reported in Figure 1a-c B 1s, C 1s and N 1s core levels appear as single peaks localized at 191.0, 286.1 and $400.0 \mathrm{eV}$ of binding energy (BE), respectively. The $\mathrm{C} 1 \mathrm{~s}$ BE position is in good agreement to that typical of $\mathrm{C}$ atoms in $\mathrm{sp}^{3}$ hybridization, as expected in the pure molecule [20,21], and the $\mathrm{B} 1 \mathrm{~s}$ and $\mathrm{N}$ 1s BE positions are in good agreement with those expected from boron, nitrogen and carbon mutually chemically coordinated with each other [22,23]. The B:C:N ratio estimated by the XPS signals, taking into account the atomic excitation cross sections [24], is 1:2.5:1, with a higher $\mathrm{C}$ content than expected in the pure molecule. This discrepancy can be explained by the presence of unavoidable carbon impurities at the very surface, since the molecular powder cannot be annealed (typical cleaning procedure to get rid of external impurities), in order to prevent its polymerization [16,17], and because XPS is a very surface sensitive technique. On the other hand, a bulk sensitive energy dispersive X-ray analysis (EDX) performed onto the powder before insertion into vacuum presents the correct ratio close to $1: 1: 1$, thus confirming the purely surface nature of the excess carbon content.

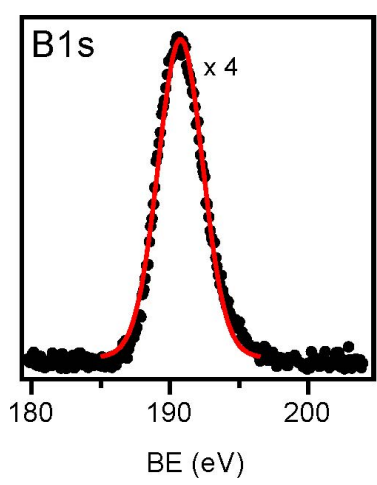

(a)

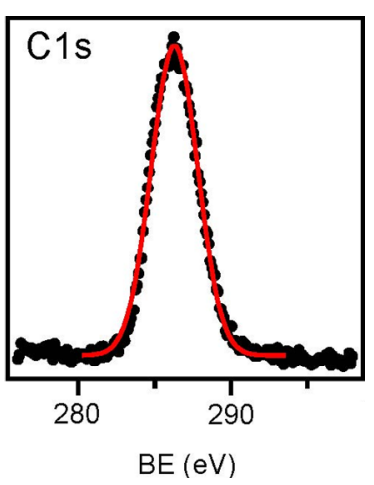

(b)

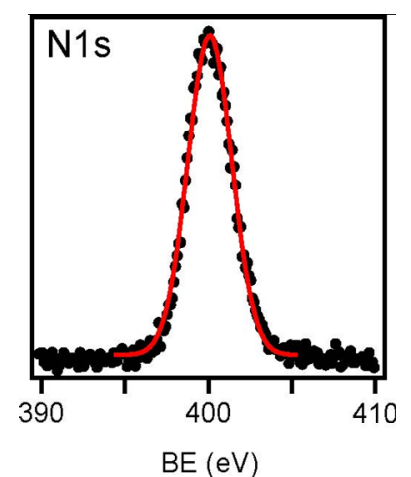

(c)

Figure 1. X-ray photoelectron spectroscopy (XPS) spectra of the (a) B 1s, (b) C 1s and (c) $\mathrm{N} 1 \mathrm{~s}$ core levels of the pure molecule.

\subsection{High Temperature Thermolysis of EDAB Investigated by Combined Thermoanalytical Methods}

The thermolytic decomposition of EDAB at high temperature (up to $1000{ }^{\circ} \mathrm{C}$ ) has been investigated by means of differential thermal analysis (DTA) coupled to thermal gravimetric analysis (TGA) and mass spectrometry (MS). The typical DTA-TGA-MS curve of EDAB recorded at $2{ }^{\circ} \mathrm{C} \cdot \mathrm{min}^{-1}$ under Ar 
flow is shown in Figure 2. It can be seen that EDAB starts decomposing at $100{ }^{\circ} \mathrm{C}$, evolving pure $\mathrm{H}_{2}$ in a two-step exothermic process below $200{ }^{\circ} \mathrm{C}$, as it was previously reported elsewhere [16,17]. Above that temperature, two additional $\mathrm{H}_{2}$ desorption events are observed, with peak maxima around 250 and $570{ }^{\circ} \mathrm{C}$. These two processes seem to be almost thermoneutral in the DTA curve. A total amount of 6.8 equivalents of $\mathrm{H}_{2}$ evolved per EDAB equivalent has been obtained by integrating the MS signal. That value is slightly lower than the total theoretical amount of $\mathrm{H}_{2}$ in EDAB, namely, 7 equivalents. This result shows that some fraction of $\mathrm{H}$ remains in the sample, namely, about $0.2 \mathrm{H}$ per EDAB equivalent, although almost all $\mathrm{H}$ is released by pyrolysis at $1000{ }^{\circ} \mathrm{C}$. Whereas the first three $\mathrm{H}_{2}$ desorption steps observed below $400{ }^{\circ} \mathrm{C}$ have been ascribed to $\mathrm{H}$ atoms coming from $\mathrm{N}-\mathrm{H}$ and $\mathrm{B}-\mathrm{H}$ groups, the high temperature desorption event observed around $570{ }^{\circ} \mathrm{C}$ is related to $\mathrm{H}_{2}$ desorption from $\mathrm{C}-\mathrm{H}$ groups in EDAB. In fact, the pyrolysis of $\mathrm{C}-\mathrm{H}$ bonds usually takes place around that temperature, since $\mathrm{C}-\mathrm{H}$ groups possess higher binding energies as compared to $\mathrm{B}-\mathrm{H}$ and $\mathrm{N}-\mathrm{H}$ ones. On the other hand, it can be observed that the mass loss recorded by TGA $(-22.8 \mathrm{wt} \%)$ is slightly higher than the theoretical mass loss corresponding to $\mathrm{H}_{2}$ desorption $(-15.6 \mathrm{wt} \%)$. The extra mass loss $(7.2 \mathrm{wt} \%)$ must be ascribed to desorption of other molecules in addition to $\mathrm{H}_{2}$. In fact, MS measurements reveal additional desorption peaks at $m / q=14,15,16$ and 27 around $570{ }^{\circ} \mathrm{C}$, suggesting the release of $\mathrm{CH}_{4}$ and $\mathrm{C}_{2} \mathrm{H}_{4}$ molecules. Additional peaks are observed at $m / q=28$ and 44 above $800{ }^{\circ} \mathrm{C}$, indicating the release of $\mathrm{CO}$ and $\mathrm{CO}_{2}$. All other MS signals in the $m / q=3-100$ range follow the same tendency than the baseline and their possible variations are within the error bars.

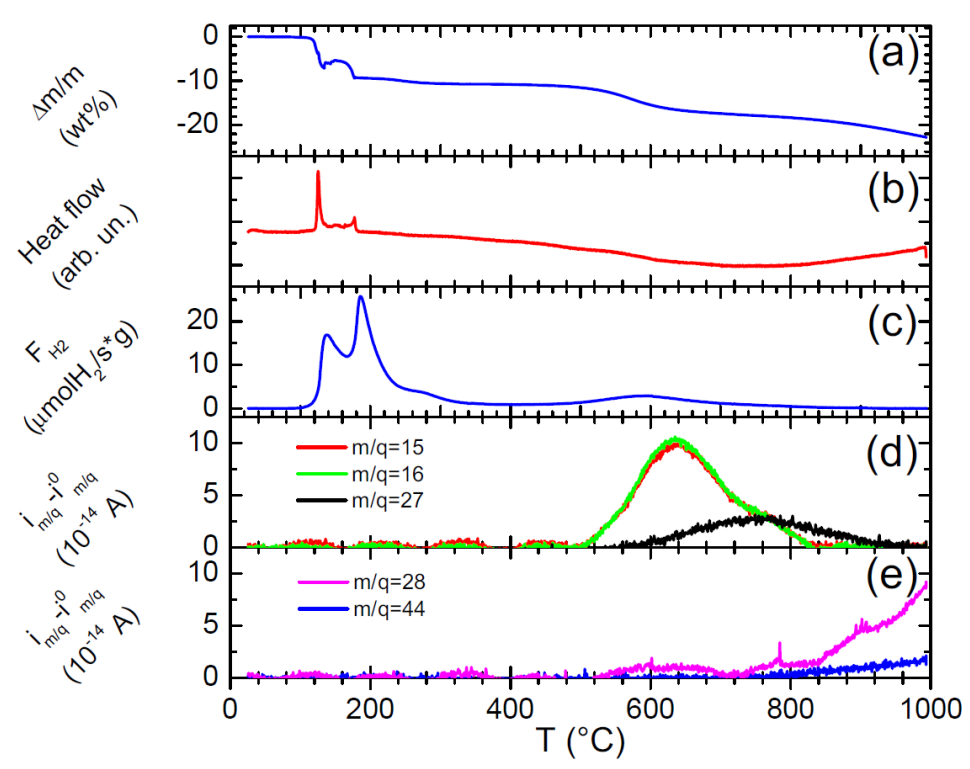

Figure 2. Differential thermal analysis-thermal gravimetric analysis-Mass spectrometry (DTA-TGA-MS) curves of ethane 1,2-diamineborane (EDAB) obtained under flowing Ar conditions at a heating rate of $2 \mathrm{~K} \cdot \mathrm{min}^{-1}$. (a) Relative mass loss $(\Delta \mathrm{m} / \mathrm{m})$ calculated from the TGA signal. (b) Heat flow recorded by the DTA apparatus. (c) Hydrogen desorbed flow $\left(F_{\mathrm{H} 2}\right)$ obtained from the $\mathrm{i}_{2}$ mass spectrometric signal. (d) Mass spectrometric ionic currents $\left(i_{m / q}-i_{m / q}{ }^{0}\right.$, where $i_{m / q}{ }^{0}$ are the corresponding baselines) at $m / q=15,16$ and 27 ascribed to $\mathrm{CH}_{4}$ and $\mathrm{C}_{2} \mathrm{H}_{4}$ desorption. (e) Mass spectrometric ionic currents at $m / q=28$ and 44 ascribed to $\mathrm{CO}$ and $\mathrm{CO}_{2}$ desorption. 


\subsection{Characterization of the Thermolysis Product}

The solid residue obtained after high temperature pyrolysis of EDAB has been characterized using different structural and chemical composition methods. Due to the fact that the thermolysis of EDAB is accompanied by significant sample foaming [17], the obtained residue appears in the shape of black foam. This sample foaming is also observed in the thermolysis of similar compounds, such as AB [1]. Typical scanning electron microscopy (SEM) images of the sample are shown in Figure 3, showing the cavities of the foamy-like products with a typical size in the $100-500 \mu \mathrm{m}$ range.

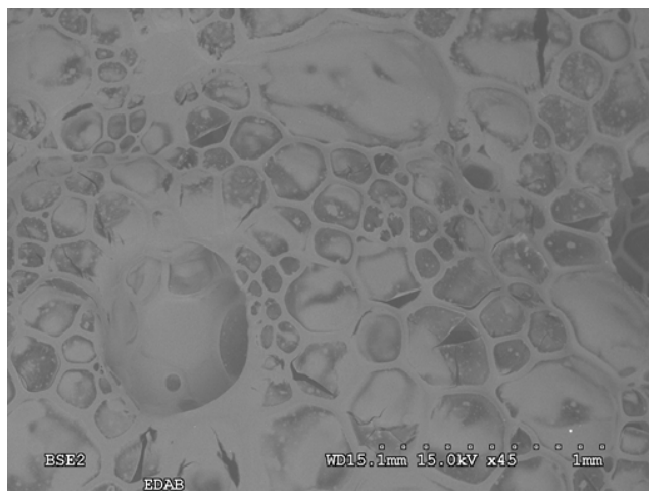

(a)

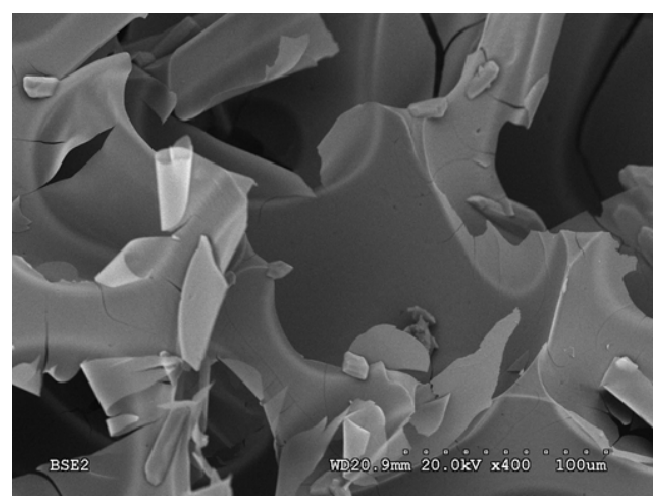

(b)

Figure 3. Scanning electron microscopy (SEM) micrographs in BSE mode (Back Scattered Electrons) of the obtained thermolysis products, taken at different magnifications: (a) $2220 \times 2950 \mu \mathrm{m}^{2}$ image size; (b) $240 \times 320 \mu \mathrm{m}^{2}$ image size.

Chemical composition has been characterized by means of EDX. These measurements give an approximate $\mathrm{B}: \mathrm{C}: \mathrm{N}$ ratio of 1:0.75:1. It must be noted that the $\mathrm{B}: \mathrm{C}: \mathrm{N}$ ratio of the $\mathrm{EDAB}$ precursor is equal to $1: 1: 1$. The depleted amount of $\mathrm{C}$ as compared to $\mathrm{B}$ and $\mathrm{N}$ in the thermolysis product seems to be caused by the observed evolution of $\mathrm{C}_{n} \mathrm{H}_{m}$ and $\mathrm{CO}_{x}$ species during high temperature thermolysis of EDAB. A considerable amount of oxygen is also observed in EDX measurements, indicating the partial oxidation of the samples. Further characterizations were also done by means of Elemental analysis. This technique, however, could not provide reliable results since the samples presented a high resistance to oxidation even at $1000{ }^{\circ} \mathrm{C}$ and therefore, combustions were incomplete. This observation confirms the high resistance to oxidation exhibited by boron nitride and other borocarbonitrides. The $\mathrm{C}, \mathrm{N}$ and $\mathrm{H}$ contents determined from the combusted fraction of the samples showed a $\mathrm{C}: \mathrm{N}: \mathrm{H}$ ratio of about 0.9:1:0.18. In spite of the limitations of Elemental analysis with these samples, it can be seen that $\mathrm{C}: \mathrm{N}$ and $\mathrm{N}: \mathrm{H}$ ratios agree reasonably well with those obtained from EDX measurements and from TGA-DTA-MS measurements, respectively.

The structural properties of the obtained residue have been also investigated by X-ray powder diffraction, as shown in Figure 4. It is observed that samples present broad diffraction peaks centered at $2 \theta=24.2^{\circ}$ and $43.0^{\circ}$. It is worth to note that this diffraction pattern is similar to those reported for BN [5] and $\mathrm{B}_{x} \mathrm{C}_{y} \mathrm{~N}_{z}$ ternary compounds [25], which are isostructural to graphite. Accordingly, the diffraction peak at $24.2^{\circ}$ has been related to (002) reflections, corresponding to the interlayer separation of the graphite-like domains. The peak at $43.0^{\circ}$ has been related to the (100) reflections and corresponds to the 
in-plane lattice parameter of the hexagonal structure. In general, peak broadening in XRPD comes from the contribution of two terms: crystal domain size and lattice parameter variations. It must be noticed that hexagonal forms of carbon, boron nitride and borocarbonitrides are isostructural with a difference of less than $2 \%$ in their lattice parameters [7]. Such small differences in lattice parameter variations cannot account for the observed peak broadening. As a consequence, the observed peak broadening seems to be mainly due to the small size of crystalline domains, which is estimated to be of about $15 \AA$, according to Scherrer formula. The observation of a poorly crystalline phase upon thermolysis of $A B$ at similar temperatures has been reported elsewhere [5].

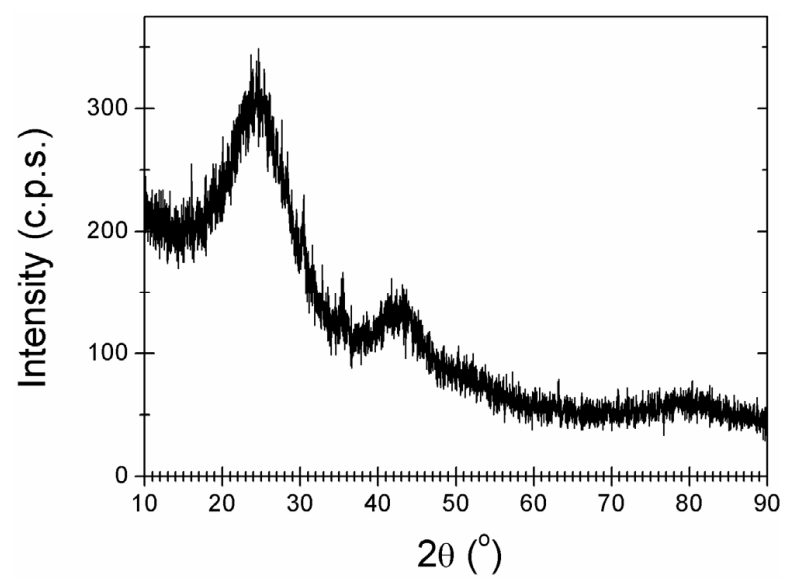

Figure 4. X-ray powder diffraction (XRPD) pattern of the product obtained by high temperature thermolysis of EDAB.

The Raman spectrum of the EDAB thermolysis product is shown in Figure 5, the sample presents broad Raman modes centered at 1350, 1590 and $2715 \mathrm{~cm}^{-1}$. The Raman band at $1590 \mathrm{~cm}^{-1}$ has been ascribed to the $\mathrm{G}$ band observed in $\mathrm{sp}^{2}$ carbon systems and other borocarbonitrides [25]. Graphitic $\mathrm{sp}^{2}$ materials also exhibit a characteristic band (called 2D-band) around $2700 \mathrm{~cm}^{-1}$. Therefore, the occurrence of 1590 and $2715 \mathrm{~cm}^{-1}$ bands in the Raman spectrum shown in Figure 5 is a clear signature of the presence of graphitic carbon. As for the band appearing at $1350 \mathrm{~cm}^{-1}$, it has been assigned to in plane B-N vibrations, as usually observed in hexagonal boron nitride [5,18] and similar borocarbonitrides [25].

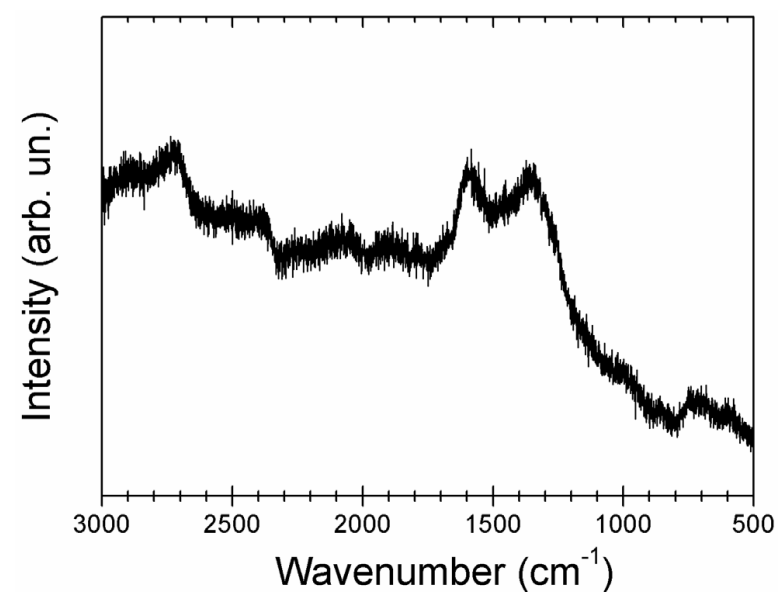

Figure 5. Raman spectrum of the sample obtained by high temperature thermolysis of EDAB. 
In order to characterize the chemical state of $\mathrm{C}, \mathrm{N}$ and $\mathrm{B}$ atoms in the obtained compound, we performed XPS measurements in ultra-high-vacuum (UHV) environment, ex situ after transferring the foamy sample into UHV. Before performing the XPS measurements, the sample has been annealed up to $300{ }^{\circ} \mathrm{C}$ in order to remove typical residual impurities adsorbed during the transfer. The XPS results are reported in Figure 6, the overview spectrum shows the presence of $\mathrm{C}, \mathrm{N}$ and $\mathrm{O}$ as main peaks, negligible $\mathrm{B}$, and $\mathrm{Cu}$ and $\mathrm{Ta}$ impurities due to the sample holder. In order to better characterize the core levels, the $\mathrm{B}, \mathrm{C}$ and $\mathrm{N}$ 1s energy regions have been acquired with higher resolution: the $\mathrm{C}$ 1s core-level is characterized by a peak centered at about $287.0 \mathrm{eV}$ of $\mathrm{BE}$, in good agreement with previous literature about synthesis of hybrid B, C and $\mathrm{N}$ compounds [25], whose energy position is different from what is expected for a pure $\mathrm{sp}^{2}$ or $\mathrm{sp}^{3}$ hybridized carbon layer [21,22,25,26], it rather reflects the line shape and $\mathrm{BE}$ of $\mathrm{C}$ atoms bonded to oxygen [27-29]. The $\mathrm{N} 1 \mathrm{~s}$ core level is characterized by a very broad peak localized at about $405 \mathrm{eV} \mathrm{BE}$, which is not typical of $\mathrm{N}$ atoms bonded to carbon or boron [23,30]. This feature can be explained by coordination of nitrogen with oxygen atoms [31], and whose width (about $6 \mathrm{eV}$ ) suggests the presence of many different un-resolved chemical species. Finally, the B 1s core level appears as very small broad feature roughly centered at $192.8 \mathrm{eV}$, corresponding to the presence of tiny traces of boron oxide species [32,33]. Moreover, we highlight that our considerations are clearly supported by the presence of oxygen as observed in the wide range spectrum, despite the sample has been annealed to high temperatures in UHV to remove surface impurities. Oxygen present at sample surface has been ascribed to sample oxidation during the thermolysis of EDAB. In fact, by taking into account the purity of the $\mathrm{Ar}$ and $\mathrm{H}_{2}$ gases and the pressure conditions used in the thermolysis experiments, the $\mathrm{H}_{2} \mathrm{O} / \mathrm{O}_{2}$ partial pressures are estimated to be in the $10^{-3}$ mbar range. By taking into account the length of these experiments, surface exposures to $\mathrm{H}_{2} \mathrm{O}$ and $\mathrm{O}_{2}$ are in the range $10^{4}-10^{5}$ Langmuir. Due to the high temperatures used in the pyrolysis experiments, surface oxidation is expected to occur under these $\mathrm{H}_{2} \mathrm{O}$ and $\mathrm{O}_{2}$ exposures. Oxidized species are very stable and do not easily decompose by high temperature annealing $\left(300^{\circ} \mathrm{C}\right)$ under UHV, thus being the dominant species observed in the XPS spectra.

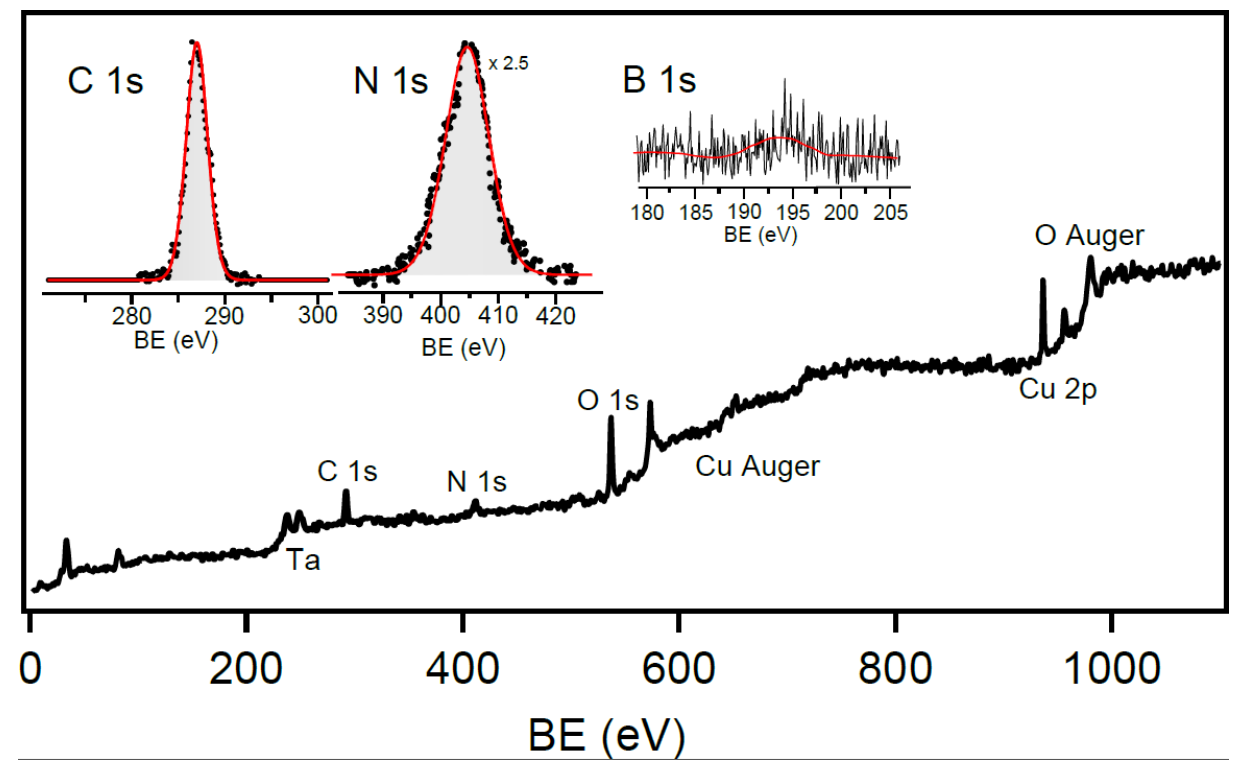

Figure 6. XPS spectra of the prepared sample after thermolysis, in ultra-high-vacuum (UHV). Complete spectral overview and detail of the C 1s, N 1s and B 1s core levels (insets). 
The B:C:N intensity ratio as estimated by XPS, showing a predominant amount of carbon, is different from what observed by the EDX analysis via SEM. This apparently contradictory result is due to the very surface sensitive character of XPS with respect to EDX. In particular, considering light elements such as carbon, the maximum estimated mean free path of the photoelectrons is less than $2 \mathrm{~nm}$ [34], much lower than the depth analyzed by EDX (about $100 \mathrm{~nm}$ ), making XPS capable to extract information only from the very first atomic layers. From this observation, our results clearly demonstrate that the bulk of the synthesized compound explored by EDX/SEM, XRD and Raman is strongly different from the surface: while the bulk of the foamy material is characterized by formation of the borocarbonitride compounds, the surface carbon and nitrogen species are predominant with respect to boron, and appear as strongly oxidized, as also confirmed by the presence of oxygen in the XPS spectra. However, we are not able to provide an accurate $\mathrm{B}: \mathrm{C}: \mathrm{N}$ ratio, since XPS performed with this photon energy is not the best technique to quantify light elements in low concentrations. In fact, in the experiment performed with $1486.7 \mathrm{eV}$ photon energy, the light elements like B present a very low excitation cross-section [24,35]. Due to these limitations, we cannot quantify the B content, but we can infer general considerations about the composition, in particular at the surface.

This combined bulk/surface sensitive spectroscopy analysis highlights how the ex situ synthesized borocarbonitride is a bulk material, whose surface is prevalently composed by $\mathrm{C}$ and $\mathrm{N}$ oxidized species covering the compound. These complementary measurements, thus, strongly suggest to perform in situ in-vacuum synthesis and characterization from EDAB to borocarboniride, a fundamental step in order to obtain and investigate the EDAB pyrolysis avoiding oxygen contamination, thus reaching the formation of a pure hybrid $\mathrm{BCN}$ phase, even at the very surface.

\section{Experimental Section}

Ethane 1,2-diamineborane (EDAB) has been supplied by Boron Specialties and used without further purification. Thermolysis of EDAB has been investigated by concomitant DTA-TGA-MS measurements (under an Ar flow of $40 \mathrm{sccm}$ ) in a DTA-TGA system (Setaram Setsys Evolution 1200, Setaram, France) coupled to a quadrupole mass spectrometer (QMS, Pfeiffer, Switzerland). The $\mathrm{H}_{2}$ detection sensitivity of QMS has been calibrated at the same experimental conditions, as described elsewhere [17]. Additional thermolysis experiments were performed in a quartz tube inserted in a tube furnace (Nabertherm Controller B 170, Nabertherm, Germany) with larger amounts of EDAB, in order to produce samples for XRPD, XPS and other characterization techniques. In those synthesis experiments temperature was monitored by using a R-type thermocouple placed outside the quartz tube. These thermolysis were done while heating under $85 \%$ Ar- $15 \% \mathrm{H}_{2}$ flow at a heating rate of $16{ }^{\circ} \mathrm{C} / \mathrm{min}$ up to $1000{ }^{\circ} \mathrm{C}$. The purity of the $\mathrm{Ar}$ and $\mathrm{H}_{2}$ gases was $99.999 \%$. The total pressure during the thermolysis experiments was always the atmospheric pressure and no pressure built-up occurred due to the gas evolution observed during the pyrolysis. The quartz tube and gas lines were checked for leaks by using an Inficon Sensitor ISH2000 hydrogen detector. EDAB was dissolved in anhydrous tetrahydrofuran (THF, Sigma Aldrich) and then deposited onto a $\mathrm{Cu}$ foil (Alfa Aesar, $25 \mu \mathrm{m}$ ), which served as an inert substrate [7-9] to growth the ternary borocarbonitrides.

X-ray diffraction measurements have been done in a X'Pert PRO diffractometer (Panalytical) with $\theta / 2 \theta$ geometry by using $\mathrm{Cu}$ K- $\alpha$ radiation. A zero diffraction plate for XRD sample holder has been used 
(silicon single crystal cut at special orientation). FTIR measurements have been done in transmission mode in a Bruker IFS66v apparatus, by mixing EDAB with $\mathrm{KBr}(1 \mathrm{wt} \%$ of EDAB) and pressing the powders into circular pellets. Scanning electron microscopy has been done in a Philips XL30 apparatus equipped with energy dispersive X-ray analysis (EDAX Dx4i). Elemental analysis has been performed with a LECO CHNS-932 apparatus. Raman spectra have been acquired in a Labram HR Raman spectrometer (Horiba Scientific, Japan) by exciting with a $532 \mathrm{~nm}$ laser.

X-ray photoelectron spectroscopy (XPS) measurements of the B 1s, C 1s and N 1s core-levels were carried out at the LoTUS surface physics laboratory (Sapienza, University of Rome) in an Ultra High Vacuum (UHV) chamber, with a base pressure in the mid $10^{-10}$ mbar range. XPS spectra were acquired with $\mathrm{Al} \mathrm{K}-\alpha$ radiation $(\mathrm{h} v=1486.7 \mathrm{eV})$, and electrons measured with the hemispherical analyser VG Microtech Clam-2 (VG Microtech, Uckfield, UK), in constant pass energy (PE) mode set at $100 \mathrm{eV}$. The binding energy $(\mathrm{BE})$ was calibrated by acquiring after each measurement the $\mathrm{Au} 4 \mathrm{f}_{7 / 2}$ core-level at a $\mathrm{BE}=84.0 \mathrm{eV}$.

\section{Conclusions}

The present work reports a novel synthesis route towards the formation of ternary borocarbonitrides. It is based on the use of a single precursor containing B, C and N. Such precursor is ethane 1,2-diamineborane (EDAB), a linear molecule of $\mathrm{BH}_{3}, \mathrm{NH}_{2}$ and $\mathrm{CH}_{2}$ groups, chemically isoelectronic to hexane. The high temperature thermolysis of EDAB has been investigated by TGA-DTA-MS experiments. EDAB shows up to four $\mathrm{H}_{2}$ desorption events below $1000{ }^{\circ} \mathrm{C}$. Small fractions of $\mathrm{CH}_{4}, \mathrm{C}_{2} \mathrm{H}_{4}$ and $\mathrm{CO} / \mathrm{CO}_{2}$ are also observed at moderate-high temperatures. This leads to the formation of a $\mathrm{B}_{x} \mathrm{C}_{y} \mathrm{~N}_{z}$ compound with traces of oxygen and some residual $\mathrm{H}$. The obtained samples have been characterized through chemical and structural methods such as SEM, EDX, Raman and XPS, confirming the formation of a poorly crystalline borocarbonitride compound. The XPS measurements, revealing a highly oxidized surface layer with respect to the bulk compound, suggest further investigation aiming at the EDAB pyrolysis in controlled UHV conditions.

\section{Supplementary Materials}

Supplementary materials can be accessed at: http://www.mdpi.com/1996-1944/8/9/5974/s1.

\section{Acknowledgments}

The authors thank Olga Caballero for her help in doing Raman measurements and to Fernando Moreno for experimental support in constructing the quartz tube for the thermolysis experiments. Some authors (Fabrice Leardini, Lorenzo Massimi, Maria Grazia Betti and Carlo Mariani) also thank Sapienza Università di Roma for financial support under "Progetti di Ateneo", and the Italian Ministry of Education and Research (MIUR) for the PRIN grant "GRAF" n. 20105ZZTSE. 


\section{Author Contributions}

Fabrice Leardini performed the TGA-DTA-MS experiments, the high temperature thermolysis of EDAB in the tube furnace and, together with Eduardo Flores-Cuevas, Jose Ramon Ares and Jose Francisco Fernández, performed the XRD, SEM-EDX and Raman characterizations and the corresponding data analysis. Lorenzo Massimi performed the XPS measurements, together with Carlo Mariani and Maria Grazia Betti analyzed the XPS data. All authors contributed to the writing of the paper.

\section{Conflicts of Interest}

The authors declare no conflict of interest.

\section{References}

1. Staubitz, A.; Robertson, A.P.M.; Manners, I. Ammonia-borane and related compounds as dihydrogen sources. Chem. Rev. 2010, 110, 4079-4124. [CrossRef] [PubMed]

2. Huang, Z.; Autrey, T. Boron-nitrogen-hydrogen (BNH) compounds: Recent developments in hydrogen storage, applications in hydrogenation and catalysis, and new syntheses. Energy Environ. Sci. 2012, 5, 9257-9268. [CrossRef]

3. Jepsen, L.H.; Ley, M.B.; Lee, Y.S.; Cho, Y.W.; Dornheim, M.; Jensen, J.O.; Filinchuk, Y.; Jørgensen, J.E.; Besenbacher, F.; Jensen, T.R. Boron-nitrogen based hydrides and reactive composites for hydrogen storage. Mater. Today 2014, 17, 129-135. [CrossRef]

4. Baitalow, F.; Baumann, J.; Wolf, G.; Jaenicke-Rößler, K.; Leitner, G. Thermal decomposition of B-N-H compounds investigated by using combined thermoanalytical methods. Thermochim. Acta 2002, 391, 159-168. [CrossRef]

5. Frueh, S.; Kellett, R.; Mallery, C.; Molter, T.; Willis, W.S.; King'ondu, C.; Suib, S.L. Pyrolytic decomposition of ammonia borane to boron nitride. Inorg. Chem. 2011, 50, 783-792. [CrossRef] [PubMed]

6. Bernard, S.; Miele, P. Nanostructured and architectured boron nitride from boron, nitrogen and hydrogen-containing molecular and polymeric precursors. Mater. Today 2014, 17, 443-450. [CrossRef]

7. Tang, Q.; Zhou, Z. Graphene-analogous low-dimensional materials. Prog. Mater. Sci. 2013, 58, 1244-1315. [CrossRef]

8. Xu, M.; Liang, T.; Shi, M.; Chen, H. Graphene-like two-dimensional materials. Chem. Rev. 2013, 113, 3766-3798. [CrossRef] [PubMed]

9. Rao, C.N.R.; Ramakrishna Matte, H.S.S.; Maitra, U. Graphene analogues of inorganic layered materials. Angew. Chem. Int. Ed. 2013, 52, 13162-13185. [CrossRef] [PubMed]

10. Dean, C.R.; Young, A.F.; Meric, I.; Lee, C.; Wang, L.; Sorgenfrei, S.; Watanabe, K.; Taniguchi, T.; Kim, P.; Shepard, K.L.; et al. Boron nitride substrates for high-quality graphene electronics. Nat. Nanotechnol. 2010, 5, 722-726. [CrossRef] [PubMed] 
11. Liu, Z.; Song, L.; Zhao, S.; Huang, J.; Ma, L.; Zhang, J.; Lou, J.; Ajayan, P.M. Direct growth of graphene/hexagonal boron nitride stacked layers. Nano Lett. 2011, 11, 2032-2037. [CrossRef] [PubMed]

12. Kim, K.K.; Hsu, A.; Jia, X.; Kim, S.M.; Shi, Y.; Hofmann, M.; Nezich, D.; Rodriguez-Nieva, J.F.; Dresselhaus, M.; Palacios, T.; et al. Synthesis of monolayer hexagonal boron nitride on $\mathrm{Cu}$ foil using chemical vapor deposition. Nano Lett. 2012, 12, 161-166. [CrossRef] [PubMed]

13. Kelly, H.C.; Edwards, J.O. Ethane 1,2-diamineborane. J. Am. Chem. Soc. 1960, 82, 4842-4846. [CrossRef]

14. Goubeau, J.; Schneider, H. Borin-anlagerungsverbindungen des athylendiamins. Chem. Ber. 1961, 94, 816-821. [CrossRef]

15. Kelly, H.C.; Edwards, J.O. Evidence for the open chain structure of ethane 1,2-diamineborane. Inorg. Chem. 1963, 2, 226-227. [CrossRef]

16. Neiner, D.; Karkamkar, A.; Bowden, M.; Choi, Y.J.; Luedtke, A.; Holladay, J.; Fisher, A.; Szymczak, N.; Autrey, T. Kinetic and thermodynamic investigation of hydrogen release from ethane 1,2-di-amineborane. Energy Environ. Sci. 2011, 4, 4187-4193. [CrossRef]

17. Leardini, F.; Valero-Pedraza, M.J.; Perez-Mayoral, E.; Cantelli, R.; Bañares, M.A. Thermolytic decomposition of ethane 1,2-diamineborane investigated by thermoanalytical methods and in situ vibrational spectroscopy. J. Chem. Phys. C 2014, 118, 17221-17230. [CrossRef]

18. Kumar, N.; Moses, K.; Pramoda, K.; Shirodkar, S.N.; Mishra, A.K.; Waghmare, U.V.; Sundaresan, A.; Rao, C.N.R. Borocarbonitrides. J. Mater. Chem. A 2013, 1, 5806-5821.

19. Ting, H.Y.; Watson, W.H.; Kelly, H.C. The Molecular and crystal structure of ethylenediamine-bisborane, $\mathrm{C}_{2} \mathrm{H}_{14} \mathrm{~B}_{2} \mathrm{~N}_{2}$. Inorg. Chem. 1972, 11, 374-377. [CrossRef]

20. Jackson, S.T.; Nuzzo, R.G. Determining hybridization differences for amorphous carbon from the XPS C 1s envelope. Appl. Surf. Sci. 1995, 90, 195-203. [CrossRef]

21. Filik, J.; May, P.W.; Pearce, S.R.J.; Wild, R.K.; Hallam, K.R. XPS and laser Raman analysis of hydrogenated amorphous carbon films. Diam. Relat. Mater. 2003, 12, 974-978. [CrossRef]

22. Ci, L.; Song, L.; Jin, C.; Jariwala, D.; Wu, D.; Li, Y.; Srivastava, A.; Wang, Z.F.; Storr, K.; Balicas, L.; et al. Atomic layers of hybridized boron nitride and graphene domains. Nat. Mater. 2010, 9, 430-435. [CrossRef] [PubMed]

23. Reddy, A.L.; Srivastava, A.; Gowda, S.R.; Gullapalli, H.; Dubey, M.; Ajayan, P.M. Synthesis of nitrogen doped graphene films for lithium battery application. ACS Nano 2010, 4, 6337-6342. [CrossRef] [PubMed]

24. Yeh, J.J.; Lindau, I. Atomic subshell photoionization cross sections and asymmetry parameters: $1 \leqslant Z \leqslant 103$. At. Data Nucl. Data Tables 1985, 32, 1-155. [CrossRef]

25. Kumar, N.; Raidongia, K.; Mishra, A.K.; Waghmare, U.V.; Sundaresan, A.; Rao, C.N.R. Synthetic approaches to borocarbonitrides, $\mathrm{BC}_{x} \mathrm{~N}(x=1-2)$. J. Solid State Chem. 2011, 184, 2902-2908. [CrossRef]

26. Scardamaglia, M.; Lisi, S.; Lizzit, S.; Baraldi, A.; Larciprete, R.; Mariani, C.; Betti, M.G. Graphene-induced substrate decoupling and ideal doping of a self-assembled iron-phthalocyanine single layer. J. Phys. Chem. C 2013, 117, 3019-3027. [CrossRef] 
27. Yue, Z.R.; Jiang, W.; Wang, L.; Gardner, S.D.; Pittman, C.U. Surface characterization of electrochemically oxidized carbon fibers. Carbon 1999, 37, 1785-1796. [CrossRef]

28. Stankovich, S.; Dikin, D.A.; Piner, R.D.; Kohlhaas, K.A.; Kleinhammes, A.; Jia, Y.; Wu, Y.; Nguyen, S.T.; Ruoff, R.S. Synthesis of graphene based nanosheets via chemical reduction of exfoliated graphite oxide. Carbon 2007, 45, 1558-1565. [CrossRef]

29. Hassoun, J.; Bonaccorso, F.; Agostini, M.; Angelucci, M.; Betti, M.G.; Cingolani, R.; Gemmi, M.; Mariani, C.; Panero, S.; Pellegrini, V.; et al. An advanced Lithium-ion battery based on a graphene anode and a lithium iron phosphate cathode. Nano Lett. 2014, 14, 4901-4906. [CrossRef] [PubMed]

30. Shi, Y.; Hamsen, C.; Jia, X.; Kim, K.K.; Reina, A.; Hofmann, M.; Hsu, A.L.; Zhang, K.; Li, H.; Juang, Z.Y.; et al. Synthesis of few layer hexagonal boron nitride thin film by chemical vapor deposition. Nano Lett. 2010, 10, 4134-4139. [CrossRef] [PubMed]

31. Polzonetti, G.; Alnot, P.; Brundle, C.R. The adsorption and reactions of $\mathrm{NO}_{2}$ on the $\operatorname{Ag}(111)$ surface: I. XPS/UPS and annealing studies between 90 and 300 K. Surf. Sci. 1990, 238, 226-236. [CrossRef]

32. Moddeman, W.E.; Burke, A.R.; Bowlin, W.C.; Foose, D.S. Surface oxides of boron and $\mathrm{B}_{12} \mathrm{O}_{2}$ as determined by XPS. Surf. Interface Anal. 1989, 14, 224-232. [CrossRef]

33. Cattelan, M.; Agnoli, S.; Favaro, M.; Garoli, D.; Romanato, F.; Meneghetti, M.; Barinov, A.; Dudin, P.; Granozzi, G. Microscopic view on a chemical vapor deposition route to boron doped graphene nanostructures. Chem. Mater. 2013, 25, 1490-1495. [CrossRef]

34. Seah, M.P.; Dench, W.A. Quantitative electron spectroscopy of surfaces. Surf. Interface Anal. 1979, 1, 2-11. [CrossRef]

35. Arab, P.; Verlander, A.; El-Kaderi, H.M. Synthesis of a highly porous bis(imino)pyridine-linked polymer and its postsynthetic modification with inorganic fluorinated ions for selective $\mathrm{CO}_{2}$ capture. J. Phys. Chem. C 2015, 119, 8174-8182. [CrossRef]

(C) 2015 by the authors; licensee MDPI, Basel, Switzerland. This article is an open access article distributed under the terms and conditions of the Creative Commons Attribution license (http://creativecommons.org/licenses/by/4.0/). 